\title{
FORMAÇÃO DO PESQUISADOR E SOFRIMENTO MENTAL: UM ESTUDO DE CASO
}

\author{
Rita de Cássia Ramos Louzada* \\ João Ferreira da Silva Filho
}

\begin{abstract}
RESUMO. Neste trabalho foram investigadas as relações entre formação de pesquisadores e sofrimento psíquico. Trabalhamos com relatos de um grupo de 21 pós-graduandos inscritos num programa de excelência, na área biomédica, numa universidade pública brasileira. Utilizamos metodologia qualitativa (método biográfico e observação participante). $\mathrm{O}$ material encontrado revelou que, neste grupo, o sofrimento psíquico faz parte do percurso acadêmico, aparece nomeado de diversas formas e em diferentes graus de intensidade. Na maior parte dos relatos o sofrimento foi relacionado a dificuldades institucionais (financiamento, por exemplo) na condução do projeto de pesquisa, na divulgação de trabalhos e no processo de "tornar-se pesquisador independente".
\end{abstract}

Palavras-chave: pós-graduação, pesquisadores, sofrimento mental.

\section{THE RESEARCH FORMATION AND MENTAL SUFFERING: A CASE STUDY}

\begin{abstract}
The relationship between researcher formation and mental suffering has been investigated in this work. Reports from a group of 21 graduate students enrolled in a biomedical excellence program at a Brazilian Federal University were analyzed. Qualitative methodology was used, comprising biographical method and participant observation. The material found revealed that mental suffering was part of the academic pathway followed by this group and appeared classified under different names and different degrees. In most reports, the suffering was related to institutional handicaps (e.g. sponsorship), difficulties in carrying out the research project, divulging the papers and "becoming an independent researcher.
\end{abstract}

Key words: graduate studies, researchers, mental suffering.

A preocupação com o impacto da formação sobre a saúde dos estudantes não é um tema novo. $\mathrm{Na}$ graduação ele tem sido bastante explorado (Firth, 1986; Grau, Arias \& Ghisays; Hudson \& O'Regan, 1994; Vitaliano, Maiuro, Russo \& Mitchell, 1989; Wolf, 1994, 1999, entre outros), mas o mesmo não se pode dizer a respeito da formação pós-graduada. Embora as pesquisas não sejam numerosas, aos poucos o tema do sofrimento vem sendo relacionado à formação de pesquisadores. Desde a década de 1970 já é possível encontrar pesquisas (Fang \& Howell, 1977; Spiro, Roenneburg \& Maly, 1979). Depois dessa década é possível encontrar maior número de pesquisas (Heins, 1984; Herzog, Norman, Rigotti \& Pepose, 1986; Helmers, Danoff, Steinert \& Leyton, 1997; Kreger, 1995; Towes, Lockyer, Dobson, Simpson Brownell, Brenneis, Macpherson \& Cohen, 1997; Tyssen, Vaglum, Gronvold, \& Ekeberg, 2001, entre outros). A maior parte do material encontrado, no entanto, tende a agrupar estudantes de graduação, pósgraduação e pesquisadores estabelecidos, sem que se especifiquem as características de estrutura e demandas exclusivas da pós-graduação.

Vale lembrar também o debate que se estabeleceu, a partir de 1998, com o suicídio, de grande repercussão,

* Doutora em Psiquiatria e Saúde Mental- Instituto de Psiquiatria da Universidade Federal do Rio de Janeiro-UFRJ. Professora Adjunta do Departamento de Psicologia Social e do Desenvolvimento da Universidade Federal do Espírito Santo-UFES.

\# Doutor em Psiquiatria - Instituto de Psiquiatria/ UFRJ. Professor Adjunto do Departamento de Psiquiatria e Medicina Legal, Faculdade de Medicina Universidade Federal do Rio de Janeiro-UFRJ. 
de um doutorando de Harvard (Schneider, 1998; Fischer, 2000) ${ }^{1}$.

No âmbito nacional, a atividade de pesquisa tem sido investigada com freqüência crescente, a partir de temas como investimentos em pesquisa, formação da comunidade científica, produtividade científica, perfil da ciência, financiamento de postdocs, pós-graduação e trabalho (Schwartzman, 1979; Leta \& De Meis, 1996; Reis, 1998; Velloso, 2002). Embora haja uma tendência a considerar a educação em ciências como uma atividade fundamental e necessária para o desenvolvimento do país, a formação de pesquisadores na pós-graduação, apenas nos últimos tempos começa a ter destaque. Isso é o que se vê nos estudos de Carmo (2001), Leta (1999), Peixoto (1994).

Enfocando especificamente o sofrimento de pesquisadores, foi possível encontrar duas pesquisas brasileiras. A primeira, conduzida por De Méis, Velloso, Lannes, Carmo e De Meis (2003), partiu de entrevistas com pesquisadores estabelecidos e pósgraduandos da área de bioquímica e identificou a existência de síndrome de burnout naquele grupo e $21 \%$ das pessoas pesquisadas com pelo menos um atendimento psiquiátrico ou psicológico. Em suas conclusões esses autores afirmam que o crescimento da ciência brasileira se dá graças a um enorme desgaste emocional das pessoas envolvidas. A segunda, realizada por Nogueira-Martins e cols.

O pós-graduando, Jason D. Altom, 26 anos, era estudante do Departamento de Química. Trabalhava no grupo do Professor de Química Orgânica, Elias J. Corey., laureado, em 1990, com o Nobel. A morte do rapaz produziu bastante comoção especialmente porque era considerado um excelente estudante. $\mathrm{O}$ debate que se seguiu relacionava-se ao fato de tratar-se do quinto suicídio na Universidade de Harvard entre 1997-1998. A partir daí a saúde mental dos alunos passou a ser pensada por aquela universidade. Isso de tal maneira que, em 2001, foi inaugurado um centro de convivência para estudantes, no prédio do Departamento de Química. A iniciativa foi comemorada pelos alunos. As matérias publicadas apresentam ainda declarações de estudantes resumidas na que se segue: "um pós-graduando pode ser muito solitário, especialmente no campo das ciências". Nesses artigos, todos de opinião, esses estudantes fizeram muitas referências à sobrecarga de trabalho num grupo de pesquisa: muitas horas de trabalho, permanência num único experimento durante meses e pressão por resultados. Todos esses itens foram considerados danosos para o cotidiano dos estudantes. Com o suicídio de Altom, esta pressão alcançou proporções críticas, impulsionando o debate que resultou em mudança quanto à orientação de alunos da pós-graduação do departamento: passouse a atribuir três orientadores, ao invés de um único, para cada estudante. Vale lembrar que Altom havia deixado um bilhete, fazendo referências ao modelo de orientação existente àquela época na instituição.
(2004), abordou, no âmbito da psiquiatria, 146 pósgraduandos (99 mestrandos e 47 doutorandos) em um centro de saúde mental da Universidade Federal de São Paulo. Observaram que a maioria dos pósgraduandos que buscaram ajuda psiquiátricopsicológica eram do sexo feminino $(68,5 \%)$ e solteiras $(71,9 \%)$. As crises apresentadas foram classificadas em crises adaptativas ou psicopatológicas. As categorias diagnósticas mais freqüentes foram: transtorno depressivo e ansioso. O artigo aponta ainda a possibilidade de identificação precoce de estudantes com distúrbios emocionais e a necessidade de encaminhamento para serviços especializados, que forneçam atenção estruturada e confidencial. Alertam também no sentido de que os orientadores e programas de pós-graduação estejam empenhados na construção de um ambiente de treinamento acolhedor.

Nossa pesquisa distingue-se desses trabalhos do ponto de vista metodológico e teórico. Aqui apresentamos relatos de sofrimento ${ }^{2}$ em doutorandos e mestrandos, ante a atual organização da pós-graduação brasileira, a partir de uma abordagem exclusivamente qualitativa. Além disso, os autores que nos guiam são: Bourdieu (1989; 1997; 2001) e os que compõem o campo da saúde mental \& trabalho (Dejours, 1988; Sato, 1992; Seligmann-Silva, 1994, entre outros). Embora nosso foco seja a formação de pesquisadores, consideramos que as mudanças observadas na pósgraduação só ganham sentido se articuladas com as que vêm sendo observadas no mundo do trabalho acadêmico/ científico $^{3}$

De acordo com Seligmann-Silva (1994), consideramos a necessidade de estudar o fenômeno do sofrimento (no nosso caso, durante a formação de pesquisadores) através de múltiplas dimensões (multiterritorialidade), que vão desde o nível micro (os estudantes e suas vivências subjetivas) até o nível macro (questões políticas, institucionais).

\section{MÉTODO}

Trata-se de pesquisa qualitativa, de tipo estudo de caso. Foram realizadas 21 entrevistas individuais, com pós-graduandos (6 mestrandos e 15 doutorandos), de

2 Dejours e Abdoucheli (1994) definem sofrimento (na situação de trabalho) como "a vivência subjetiva intermediária entre a doença mental descompensada e o conforto (ou bem-estar) psíquico".

3 Este trabalho faz parte de uma pesquisa mais ampla onde são articulados os temas da formação, do trabalho científico e da saúde mental de pós-graduandos brasileiros (Louzada, 2005). 
ambos os sexos, na faixa etária de 25 a 52 anos, na maioria solteiros. Os entrevistados compunham a totalidade dos estudantes de dois laboratórios de um mesmo programa de pós-graduação. Todos estavam, à época da pesquisa, formalmente matriculados nesse programa de pós-graduação, nível de excelência, na área biomédica, de uma universidade pública brasileira. Apenas uma minoria dos sujeitos possuía ascendentes familiares envolvidos com pesquisa (professores universitários ou pesquisadores). A maioria era oriunda de classe média, filhos de pequenos comerciantes, funcionários públicos $\mathrm{e}$ profissionais liberais. Apenas um sujeito tinha origem rural. Os pós-graduandos, na maioria, dedicavam-se exclusivamente às atividades do curso. Dois deles, além da pós-graduação, mantinham vínculos trabalhistas: um como professor substituto (universidade pública) outro como professor efetivo em universidade privada. Vale destacar também que um dos sujeitos era aposentado.

As entrevistas foram conduzidas conforme o método de história de vida (tópica) (Minayo, 1994). Trabalhou-se, portanto, com entrevistas abertas. Na pergunta inicial solicitava-se ao sujeito que caracterizasse seu percurso acadêmico; seguia-se então uma conversa, com liberdade ao entrevistado de tematizar e temporalizar a seu modo. As interferências do entrevistador visavam esclarecer pontos/temas levantados pelo próprio pós-graduando e incluir, caso não surgissem no relato, os temas "escolha da profissão/atividade", "dia-a-dia da pesquisa" e "vivências de sofrimento e prazer".

As entrevistas foram gravadas, integralmente transcritas e submetidas, posteriormente, à análise de conteúdo (Bardin, 1987). Além das entrevistas, foi possível também contar com dados recolhidos a partir da observação participante de algumas atividades desenvolvidas no departamento (seminários, cursos, cotidiano de laboratórios), durante os anos de 1999 e 2000.

\section{$1^{0}$ TERRITÓRIO: O CENÁRIO INSTITUCIONAL}

À época da pesquisa, a atividade científica no Brasil vivia momentos difíceis em função de importantes restrições orçamentárias e, além disso, inúmeras transformações estavam em curso no âmbito acadêmico-científico.

Primeiramente, destacamos que as diretrizes da universidade brasileira - onde a maior parte das

4 Para este artigo apenas o tema do sofrimento foi considerado. pesquisas nacionais vem sendo realizada - têm se modificado rapidamente, e isso em sintonia com tendências internacionais (Easthope \& Easthope, 2000; Slaughter \& Leslie, 1999). Um marco importante foi a edição da Lei de Diretrizes e Bases da Educação Nacional, em 1996, que definiu, por exemplo, categorias diferenciadas de instituições de ensino superior. Outro dado é o flagrante esvaziamento das instituições públicas de ensino superior. Um exemplo aqui é a relação professor/estudante nesse âmbito: atualmente, cerca de 50 mil professores lecionam nessas instituições, sem que se altere esse contingente desde o início da década de 1990; já o número de alunos cresceu bastante nesse período (de 356 para 600mil).

Em segundo lugar, observamos um crescimento importante da pós-graduação brasileira nos últimos anos, bem como da produção científica e do número de alunos nesse nível de formação ${ }^{5}$.

Em terceiro lugar, registre-se que o fomento à pesquisa no país esteve praticamente estagnado de 1998 a 2000, ano em que o Governo Federal acenou com um conjunto de medidas que instituíam um novo sistema nacional de fomento à pesquisa, com recursos dos "fundos setoriais",

Por último, deve ser destacada a Lei de Inovação Tecnológica, recentemente aprovada. Esta lei vem sendo apontada como peça-chave para o desenvolvimento da ciência e tecnologia nacionais na medida em que articula o trabalho de pesquisa realizado em instituições públicas com as atividades empresariais.

Ao menos estes eventos e tendências, mais nítidos a partir de meados da década de 1990, trazem como conseqüência um ritmo intenso nas atividades das pósgraduações. Surgem novas exigências para que se alcance o nível de excelência em pesquisa. Os programas de pós-graduação passam a ser mais cobrados no que se refere à produtividade científica e estimula-se a conclusão mais rápida de cursos de mestrado e doutorado. A mudança incide diretamente nos programas de pós-graduação, mas também sobre os docentes-pesquisadores, pós-graduandos e candidatos à pós-graduação. Ao contrário do que apontam alguns autores, a cultura da produtividade não se restringe a níveis departamentais. Esta passa a

Cf. discurso proferido pelo Presidente da República em 3/4/2000 (Jornal da Ciência, 14/4/2000).

6 O lançamento da nova proposta quanto ao sistema de financiamento da pesquisa científica e tecnológica brasileira foi feito em 3/4/2000 pelo Presidente da República. (Jornal da Ciência, 14/4/2000). Vários fundos já se encontram em funcionamento. 
ser, a partir de determinado momento, a regra para avaliações de todos os programas de pós-graduação no país.

Em resumo, à época dessa pesquisa existiam nas pós-graduações brasileiras um grande contingente de alunos, aumento do número de titulados a cada ano (6.000 em média), cobrança de produtividade (especialmente via publicações) e preocupação com o tempo médio de titulação. Tal quadro traz como conseqüência uma maior sofisticação nos processos seletivos e termina por valorizar a "real capacidade" de produção dos futuros alunos, com a criação de estágios - assim nomeados ou não - anteriores à entrada formal nos cursos de pós-graduação.

\section{$2^{\circ}$ TERRITÓRIO: O AMBIENTE DA FORMAÇÃO ${ }^{7}$}

Os relatos colhidos apontaram, no âmbito do programa de pós-graduação em foco, exigência de grande dedicação à atividade de pesquisa. Isso podia incluir finais de semana e até 12 horas de atividade diárias, a depender somente das exigências das atividades desenvolvidas pelo pós-graduando.

As disciplinas que os alunos deviam cumprir, para compor os créditos necessários à conclusão do curso, eram em geral curtas e condensadas, de modo que a maior parte de suas atividades durante o curso concentravam-se na pesquisa propriamente dita.

Os pós-graduandos tinham uma inserção institucional importante, com a participação em cursos para estudantes de níveis inferiores; trabalhavam também na confecção de relatórios, projetos para a captação de recursos e atividades de manutenção do laboratório (compras, obras, segurança). Tais atividades tomavam como referência o dia-a-dia e as necessidades dos laboratórios, muito mais do que o do próprio departamento, e em geral os projetos individuais eram muito articulados entre si e com a linha de pesquisa mais geral de cada laboratório.

As relações entre os pós-graduandos eram obrigatoriamente próximas, já que permaneciam muitas horas diárias naquele local, compartilhando aparelhos/instrumentos e espaços. A qualidade dessas relações variava, segundo os alunos, conforme a liderança do laboratório, as características dos próprios estudantes e a forma como o trabalho era desenvolvido. Foi possível ouvir de alguns pósgraduandos que se sentiam em família e de outros que

7 A maior parte das informações contidas neste item baseouse nas observações feitas a partir do cotidiano dos laboratórios e algumas atividades do programa/departamento. não conseguiam ter muitos amigos ali. De maneira geral, no entanto, os entrevistados falavam de um relacionamento institucional bom e afirmavam que uma característica do departamento era a solidariedade. A isto relacionavam, especificamente, a grande disponibilidade no compartilhamento de aparelhos, reagentes e informações entre os laboratórios. Uma via para aferir esta última característica era a intensa comunicação eletrônica entre os estudantes, docentes e funcionários do departamento, onde se podiam ver mensagens sobre eventos, solicitações de bibliografia, reagentes, instrumentos etc.

A relação dos pós-graduandos com seus orientadores também era digna de nota. Em geral os pós-graduandos sentiam-se apoiados por seus orientadores. Estes, no entanto, nem sempre estavam disponíveis, o que terminava produzindo a prática da chamada "orientação em cascata", em que alunos mais avançados apoiavam os mais novos nas atividades acadêmicas, gerando estreitas relações de pesquisa entre doutorandos, mestrandos e alunos de iniciação científica, em projetos estreitamente articulados.

Outra observação importante é que a formação desses jovens pesquisadores ocorria num ambiente onde as trocas eram inúmeras, tanto interna quanto externamente (nível nacional e internacional). Como resultado do ritmo intenso de trocas científicas observava-se, por exemplo, a inserção de alunos muito jovens em projetos de grande complexidade.

Embora existissem, no momento da pesquisa, importantes restrições orçamentárias ao setor de ciência e tecnologia, a maior parte dos pósgraduandos desse programa recebia apoio financeiro de agências de fomento brasileiras. Além disso, muitos deles encontravam-se envolvidos em (ou em busca de) colaborações com outros departamentos e instituições.

\section{$3^{0}$ TERRITÓRIO: AS VIVÊNCIAS DE SOFRIMENTO}

Nas entrevistas, todos os pós-graduandos fizeram referência a algum tipo de mal-estar, atual ou pretérito. Tal como apontado nas pesquisas realizadas por Dejours (1988) e sua equipe, o mal-estar que aparece em nossos dados não pode ser caracterizado como doença mental, em sentido estrito. O que temos, na maioria dos casos, são vivências de sofrimento nomeadas de várias formas: "angústia", "estresse", "preocupação"; "ansiedade"; "tensão", como 
poderemos ver adiante ${ }^{8}$. Além disso, vale ressaltar que as referências a vivências de sofrimento foram apresentadas pelos entrevistados em intensidades e freqüência muito singulares, variando desde uma simples preocupação até um intenso mal-estar, tristeza, somatização ou depressão. Essas vivências, de modo geral, foram relacionadas, no percurso acadêmico, a:

- condução do projeto de pesquisa;

- divulgação de trabalhos;

- "tornar-se pesquisador independente";

- problemas institucionais.

A condução do projeto de pesquisa foi muito referida como produtora de mal-estar. Os entraves observados foram relacionados especialmente ao próprio processo de construção do conhecimento, que é complexo: os pós-graduandos precisam trabalhar, ao mesmo tempo, com um grande volume de pesquisas já realizadas (através da leitura de artigos, livros) e com suas próprias idéias, num esforço contínuo de articulação. Além disso, precisam contar com recursos materiais, nem sempre existentes. O ritmo da pesquisa, portanto, é dependente de inúmeras variáveis, que se relacionam com as características do campo estudado, a criatividade do pesquisador, o relacionamento com o orientador, os recursos existentes, o volume de discussão no ambiente de trabalho, as características do projeto, o tamanho do laboratório, as exigências das agências de fomento etc.

Diante de tudo isso, os pós-graduandos detalharam esse item, de tal maneira que foi possível identificar subcategorias. As dificuldades na condução da pesquisa foram mais relacionadas a:

- definir/mudar o problema da pesquisa;

- ausência de resultados/montagem de uma história a partir dos experimentos;

- existência de múltiplos projetos/tarefas simultâneos.

Quanto a definir/mudar o problema da pesquisa, destacamos dois relatos: um de uma doutoranda e o outro de uma mestranda, respectivamente:

"Eu acho que eu tinha um pouco de resistência, tinha muita coisa que eu ainda queria fazer mas... Enfim, realmente tinha

Colhemos apenas um relato de doença (depressão), com necessidade de acompanhamento psiquiátrico e psicológico. Isto, no entanto, não quer dizer que inexistiam outras situações semelhantes, mas apenas que não nos foram relatadas. que mudar porque eu não ia ter uma coisa assim, que fosse dar uma tese de doutorado...Agora... algumas coisinhas que eu gostaria de ter feito, mas enfim...Aí no começo [do doutorado] eu ainda estava resistindo a.. a mudar, como se fosse assim: aquele não é o meu trabalho, né? Até passar a ser o meu trabalho demorou um pouco [pausa longa] [...] O trabalho de mestrado principal foi tudo eu que decidi fazer, desde o começo... [...] Eu sentia um objetivo, eu queria provar uma coisa....uma idéia que eu tinha tido. Foi um trabalho muito... é.. recompensante, né? Já no doutorado não..."

"Eu ainda não sei te dizer qual que é a minha questão hoje, sabe?"

No primeiro relato aparece a "resistência" a mudar de projeto, na passagem do mestrado para o doutorado. Essa dificuldade foi relacionada ao interesse em terminar ou dar continuidade ao projeto anterior. O relato é interessante na medida em que a aluna revela sua "estranheza" em relação ao novo projeto. Por indicação de seu orientador, engajou-se nessa nova pesquisa, cujas bases já haviam sido lançadas em projeto anterior do próprio laboratório. Tratava-se, portanto, de uma adequação de seu próprio caminho acadêmico à experiência de sucesso de uma determinada linha de pesquisa daquele laboratório. Isso levou tempo ("até passar a ser o meu trabalho demorou um pouco”). Ou seja: a idéia gestada no nível do mestrado teve de ser abandonada, produzindo "estranheza" na relação com o novo tema, no doutorado.

Esta situação articula-se com um relato ouvido, numa conversa informal, de uma pesquisadora que já havia passado por aquele departamento, a respeito de "projetos institucionais":

"O fato é que você precisa ter claro que [ali] você faz parte de um grupo e que o teu projetinho faz parte de um projeto maior. Só assim as coisas fazem sentido".

Dito de outra maneira, a possibilidade de experimentar mal-estar ou bem-estar quanto a esse modo de organização da pesquisa parece ter relação direta com o modo como o estudante "vê" a situação; e ele "vê" mais ou menos naturalmente, conforme o maior ou menor êxito de seu processo de ordenação (Bourdieu, 1989), ou seja, em função do processo de socialização a que foi/é submetido, dos valores e 
comportamentos que vai assimilando para, efetivamente, poder tornar-se um elemento daquele curso/departamento.

O mesmo se pode dizer com relação à afirmação segundo relato citado - de uma mestranda a respeito de não saber "qual é sua questão para a pesquisa". Embora apresentasse linhas gerais de interesse, essa aluna, formalmente matriculada no mestrado, não tinha definido, no início de seu curso, o problema sobre o qual iria trabalhar. Isto faz pensar nos prérequisitos para a admissão. Peixoto (1994), interessada na formação de pesquisadores e tendo entrevistado alunos e professores de cursos de pós-graduação, nível A, no Rio de Janeiro, assinalou que havia, na época de sua pesquisa, grande diversidade de critérios para a seleção nos diferentes programas de pós-graduação: em alguns deles exigia-se, por exemplo, a definição do projeto a ser desenvolvido, em outros, não.

No programa em foco havia, sem dúvida, grande peso para o envolvimento anterior no trabalho de pesquisa, muito mais do que exigências de definições claras e sistematizadas a respeito do futuro projeto. Tal característica podia ser percebida na forma como a maioria dos pós-graduandos entrevistados havia chegado ao departamento: via iniciação científica ou cursos de atualização. Estas atividades poderiam evoluir, no tempo e conforme o interesse das partes (orientador e orientando), para outros níveis de treinamento, até alcançar (ou não) a pós-graduação stricto sensu' ${ }^{9}$.

Vale notar que, embora a maioria dos pósgraduandos estivesse nos laboratórios desde algum tempo, as idas e vindas do trabalho científico apareceram como produtoras de angústia:

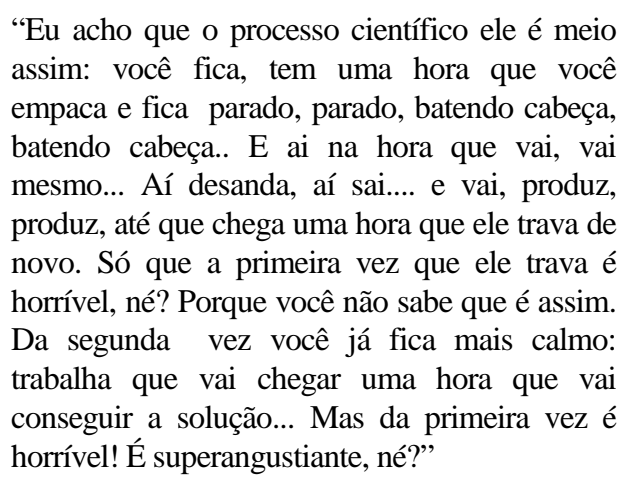

9 Ouvimos de alguns entrevistados que esse era um processo de "seleção natural", expressão que desde sempre estranhamos.
Este momento, em que a pesquisa "fica parada" é também referido como ausência de resultados. Pode ocorrer em função do próprio processo de construção do conhecimento, por problemas inerentes ao projeto ou por dificuldades do pós-graduando numa técnica específica. De toda maneira, pode produzir mal-estar, como aponta também esta outra pós-graduanda:

"Às vezes você começa a fazer uns experimentos e as coisas vão se encaixando. Então vai meio que contando uma historinha, né? Aí fica bonitinho, mas às vezes não, às vezes você tem um monte de resultado...e agora, o que que eu faço?"

Aqui se vê claramente que, diante da inexistência de regularidade nos resultados, ou seja, ausência de resultados, surge uma vivência de dúvida ("o que que eu faço?"). O pressuposto neste último relato é que, através do processo de fazer e refazer experimentos, o caminho da pesquisa será encontrado. Esta é, sem dúvida, uma parte do trabalho de pesquisa que realizam, mas, além disso, tal atividade exige articulação com um volume de conhecimento do campo que é, em geral, requerido (encontrado) do (no) orientador. Essa foi uma vivência de entrevistados de ambos os níveis - variando conforme as características do percurso na pesquisa - mas especialmente de mestrandos.

Vale lembrar, aqui, o achado de Alvarez (2001/ 2004) em pesquisa com físicos brasileiros. Falando do trabalho oculto, mental, na atividade dos físicos, a autora identifica frustração e a ansiedade produzida no contato alongado com as idéias, inicialmente pouco sistematizadas; a incerteza com relação à viabilidade de determinado projeto/problema e a frustração por dificuldades na obtenção de resultados. Embora este não fosse o foco da pesquisa, Alvarez ouviu com freqüência referências a alterações no sono de seus entrevistados.

Outra fonte de mal-estar foi citada inúmeras vezes: as múltiplas tarefas simultâneas. Se, por um lado, essa experiência traz uma amplitude maior à formação do pós-graduando, por outro pode significar interferências no tempo para o desenvolvimento de projeto de tese/dissertação. As tarefas mencionadas, para além da própria pesquisa, tinham caráter didático, mas também foram mencionadas: confecção de relatórios/projetos, seleção de alunos para cursos de atualização e atividades relacionadas ao cotidiano do laboratório para as quais inexistiam funcionários do staff (compras, controle de segurança). 
Essa multiplicidade de atividades também aparece no relatório de um workshop sobre educação pósgraduada, na área de Química ${ }^{10}$, realizado nos EUA. Em determinado momento acompanha-se uma reflexão a respeito do duplo papel do pós-graduando: aluno e instrutor.

\begin{abstract}
Graduate students have just come from an environment in which faculty talked at them. Now, they have to adjust to a new living environment, figure out the university`s bureaucracy, excel in graduate courses, find a research advisor and, by the way, they have to teach.

[...] They have only watched others teach, and then we ask them to teach. They have read about science and done directed laboratory experiments, but have done very little research, yet we expect them to know what science is all about [...] Moreover, they have to teach in the way that we dictate, which may or not be consistent with their owns views about teaching (National Academy of Sciences, 2000, p. 75)
\end{abstract}

Tais preocupações poderiam ser consideradas também para pensar as atividades de pós-graduandos brasileiros. Tal como a função de ensino, pósgraduandos brasileiros de algumas áreas também são requisitados a desenvolver inúmeras outras tarefas para além do projeto de tese; e a resposta a esse tipo de demanda, não há negar, relaciona-se diretamente com a consciência que esses pós-graduandos têm do alto nível de competição a ser enfrentado para a futura inserção laboral ${ }^{11}$.

Outro item relacionado ao mal-estar foi a divulgação de trabalhos. Surgiram respostas envolvendo dificuldades em escrever, em lidar com a rejeição de artigos e com a competição no momento da publicação. Os entrevistados tinham clareza a respeito das desigualdades existentes na estruturação do campo científico e sua influência no momento do reconhecimento de seus trabalhos pelos periódicos considerados "bons". O mesmo se pode dizer a respeito das condições em que se formam, consideradas "adversas": o tempo de duração dos cursos e a fragilidade das bibliotecas são especialmente citados.

10 Cf. National Academy of Sciences (2000)_Graduate Education in the Chemical Sciences. Issues for the $21^{\text {st }}$ Century: Report of a Workshop.

11 Vale confrontar a discussão realizada por Louzada e Silva Filho (2003) a esse respeito.
De Méis, Velloso, Lannes, Carmo e De Meis (2003) já apontaram que a publicação transformou-se no momento mais importante para o pós-graduando brasileiro, em detrimento da defesa da tese. Por isso, a rejeição de artigos, por exemplo, pode ser vivida como rejeição ao próprio pós-graduando, uma forma de nãoreconhecimento ao seu "talento científico" 12

Além de problemas na condução e divulgação da própria pesquisa, apareceram também muito citadas as dificuldades em "tornar-se um pesquisador independente". Embora não tivessem vivenciado diretamente essa dificuldade, na medida em que ainda estavam em formação, os pós-graduandos falavam sobre quão delicado esse processo pode ser. Para "tornar-se um pesquisador independente" eles devem: obter financiamento, orientar alunos de pósgraduação, publicar sem o auxílio do orientador e ter sua própria linha de pesquisa. Alguns relatos:

“[é] uma parte dura [...] acho que todo mundo passa por isso mesmo. Eu acho que essa parte de você estabelecer uma linha de pesquisa... [Isso] te angustia assim[...]"

"[...]isso [fazer pesquisa de forma independente] gera um estresse grande".

Ou seja, se por um lado esses pós-graduandos formam-se numa relação estreita com o eixo temático do laboratório - fenômeno já apontado como característica muito marcante na ciência brasileira (Reis, 1998) - por outro sabem quão importante é separar-se disso, ter/definir uma linha de pesquisa ao final do doutorado. Somente a partir daí podem, efetivamente, pensar em alcançar todos os requisitos exigidos a um "pesquisador independente".

Esta não é uma realidade exclusiva desses estudantes ou dessa pós-graduação. Os jovens pesquisadores americanos, por exemplo, também encontram dificuldades semelhantes ao final do curso. Segundo Stephan e Mangematin (1997),

Ils doivent prouver, en particulier, qu'ils sont capables de créer leur propre laboratoires, c'est-à-dire de trouver les fonds pour faire fonctionner le laboratoire (non seulement por acheter les matériaux et équipements mais aussi pour payer les assistants de recherche - des étudiants de niveau maîtrise -, pour financier des postdoc et des techniciens), fonction que

12 Vale lembrar que esta exigência (publicação), por vezes durante a pós-graduação, é relativamente recente no país e existem indícios de sua relação com o aumento da produtividade científica brasileira. 
relève de la responsabilité individuelle du chercheur, l' université fournissant les financements nécessaires au démarrage (Stephan \& Mangematin (1997,p. 38).

Outra relação estabelecida, nos relatos, com o sofrimento vivenciado foi com problemas institucionais. As respostas incluíam a rotina no próprio laboratório, a estrutura da pós-graduação, a universidade e as instituições financiadoras. Uma pósgraduanda se queixa do ritmo de trabalho no laboratório e observa:

"[...] hora de almoço é hora de almoço, as pessoas têm que entender que têm que almoçar. Não têm que ficar fazendo journal, têm que almoçar, têm que dar chance ao estômago, têm que dar chance ao corpo, né?!"

Outros pós-graduandos estranham as regras das agências de fomento:

"Ela [instituição financiadora] quer que você
tenha as coisas bem estabelecidas, que você
cumpra o cronograma do seu projeto, mas
enfim como é impossível você estabelecer
um projeto sem surgirem questões?... É meio
imprescindível que eles tenham uma certa
flexibilidade com relação a mudanças ou
eventuais novas perguntas que possam surgir.
Mas não é muito fácil [...] eles não querem
nem saber, eles querem saber de resultados!"

Outra entrevistada acrescenta uma regra do programa de pós-graduação que imprime determinado ritmo ao final do curso:

"Mas aqui pra defender o doutorado você tem que ter um artigo aceito, também, né? Então eu tenho que correr porque em geral as revistas demoram 2 ou 3 meses pra responder, enfim, tem que correr, mandar logo o artigo, e isso que tá mais estressando e a questão dos elementos que não pode deixar de ir, né, no primeiro artigo... Mas eu acho que essa semana eu acabo de resolver e fecho. Aí vai demorar mais um mês pra eu fechar as coisas todas do artigo e mandar o artigo."

Dito de outra maneira, há características na organização desse trabalho que impactam os sujeitos produzindo, eventualmente, mal-estar (Dejours,1988; Dejours \& Abdoucheli, 1994). Esta é uma constatação importante na medida em que torna coletiva uma experiência que, quando chega a ser expressa, é feita apenas no singular.

As vivências subjetivas de pós-graduandos tomados aqui como pesquisadores de fato - talvez possam ser, em parte, aproximadas às dos pilotos de caça, estudados por Dejours (1988). Esse autor nos informa que os pilotos passam por uma "corrente seletiva", que envolve rígida seleção física, intelectual e psíquica. Quanto a esta última Dejours nos diz: "ela resulta do jogo oculto das relações que acompanham a progressão do aluno desde os testes de entrada até a qualificação de piloto operacional" (p. 94). Tal situação pode, a nosso juízo, ser aproximada à atividade dos pós-graduandos aqui estudados, na medida em que estes são também permanentemente avaliados. Vários de nossos entrevistados chamaram esse processo de "seleção natural", expressão que descreve o que ocorre no caminho da formação. Nesse caminho ocorrem algumas desistências de candidatos a pesquisadores. Segundo alguns relatos, os candidatos que ficam pelo caminho "descobrem que aquela não é a sua praia" ou "não se divertem muito com a atividade".

Além disso, talvez se possa dizer que, tal como os pilotos de caça, os pós-graduandos precisam se manter sempre motivados, em suas palavras: "muito envolvidos", em "busca de excelência", "antenados". Vale lembrar que os pilotos de caça estudados por Dejours, quando não desejavam voar, eram rapidamente eliminados da equipe.

Em resumo, é mister notar que os relatos de malestar aqui apresentados podem ser separados em duas grandes categorias. Numa primeira categoria ficam os que continham as vivências mais agudas de sofrimento. Todas essas referidas como pretéritas e superadas com o apoio de orientadores, da instituição (tolerância quanto a prazos, por exemplo) e eventualmente de profissionais de saúde (psiquiatra, psicólogo). Numa segunda categoria de relatos apareceram as vivências mais leves e ocasionais. O material colhido, sem dúvida, tem a configuração do que é passível de verbalização, dadas as circunstâncias existentes no momento da pesquisa (condições/relações de trabalho no laboratório; o momento da formação e as demandas existentes; a relação estabelecida com a entrevistadora, entre outras).

\section{CONSIDERAÇÕES FINAIS}

Os dados colhidos revelaram que o sofrimento faz parte do processo de formação dos pesquisadores entrevistados; manifesta-se em diversos níveis de 
intensidade e aparece nomeado de múltiplas formas. É certo que o tema foi detalhadamente explorado por poucos, mas referido por todos, ainda que tangencialmente. Eventualmente esse sofrimento apareceu naturalizado; mas foi possível vê-lo também remetido a determinadas regras existentes no campo científico.

Resgatando os estudos do campo da saúde mental e trabalho, é possível dizer que o sofrimento expresso por esses sujeitos não pode ser compreendido sem que se considere a organização do trabalho a que estão submetidos. Se, como vimos, o sofrimento é apresentado como natural por alguns pós-graduandos, isso revela, de antemão, a desconsideração da organização do trabalho como fator relevante nesse processo de formação. No entanto, foi também possível encontrar outros estudantes que fizeram referência às condições e relações de trabalho na atividade de pesquisa. Isso inclui o ambiente do laboratório e a cultura organizacional; mas não apenas. Há que se dar destaque também às regras acadêmicas, aos critérios definidores do sucesso científico por parte das instituições financiadoras, ao próprio processo de financiamento e sustentação da atividade de pesquisa. Em suma, há que considerar, no mínimo, as políticas educacionais e de ciência e tecnologia vigentes no momento estudado.

Como nos diz Bourdieu (2001), a ciência se configura como campo, numa luta constante de grupos e indivíduos pelo poder de nomear, pelo poder de dizer o que é e o que não é cientificamente relevante. Além disso, é necessário, segundo o mesmo autor, identificar a posição de determinado laboratório ou pesquisador dentro do campo. Ou seja, a aprovação ou não de um projeto ou artigo, por exemplo, está relacionada a seu mérito, mas também à origem desse trabalho.

Salvo melhor juízo, nossos achados possibilitam ampliar a noção de ordenação, tal como concebida por Bourdieu. Segundo esse autor, o processo de ordenação pode levar, a depender da forma como é conduzido, ao êxito ou ao fracasso na carreira escolar. A nosso juízo, talvez se possa falar desse processo de ordenação como um continuum, onde o êxito e a falência completa estivessem no limite, as gradações nesse processo pudessem ser consideradas e o sofrimento incluído como um índice das dificuldades existentes durante a formação; dificuldades que, esperamos tenha ficado claro, não se reduzem ao estudante, à relação orientador-orientando, ao ambiente de formação, ao financiamento ou possibilidades de inserção laboral no futuro, mas atravessam todos esses territórios. Ou seja, faz-se mister considerar: as relações e condições de trabalho; as regras de fomento; a equipe de pesquisa; as colaborações estabelecidas; a posição do laboratório no campo; o nível de reconhecimento científico do orientador; a posição do programa de pós-graduação; o estilo do orientador etc. Esses arranjos são absolutamente singulares. Não há um único modo de organizar um laboratório ou departamento, estabelecer colaborações ou parcerias em ciência. Muito menos uma única maneira de os estudantes responderem às exigências da formação científica. Não há, enfim, um único modo de fazer pesquisa nem de formar pesquisadores. As combinações possíveis entre todas as variáveis citadas, não há negar, impactam o processo de formação como um todo e exigem reflexão permanente.

Os resultados dessa pesquisa, por conta de tudo o que foi dito anteriormente, devem ser cuidadosamente considerados, na medida em que trabalhamos com um grupo muito específico de sujeitos; mas ao mesmo tempo se faz mister reconhecer que todos programas de pós-graduação do país - no momento atual - são levados a funcionar em padrão semelhante. Talvez se possam considerar esses dados como indicadores de uma determinada forma de fazer ciência e de formar pesquisadores, com consequiências bastante complexas e singulares para os pós-graduandos; e essa complexidade, segundo alguns autores (AllenCollinson, Hockey \& Pourmir, 1998), os surveys não conseguem acessar.

Por fim, levando em conta o aumento do número de pós-graduandos em nosso meio e as dificuldades de inserção laboral dos jovens pesquisadores, nossos achados apontam para: (1) a necessidade de uma escuta mais cuidadosa desse tipo de fenômeno (sofrimento), nem sempre assumido, conforme também apontado em Pourmir (1998) e (2) a urgência de políticas, ao menos nos campos da educação e da C\&T, que abram, nas instituições universitárias e de pesquisa, espaços de produção compatíveis com as especificidades dessa atividade e que abarquem não apenas os resultados, mas principalmente as singularidades existentes no processo de trabalho científico.

\section{REFERÊNCIAS}

Allen-Collinson, J. \& Hockey, J. (1998). Capturing contracts: informal activity among contract researchers. British Journal of Sociology of Education, 19, 4, 497-513. 
Alvarez, D. (2004). Le "travail occulte" des chercheurs: objet et matière invisibles. Les territoires du travail. 8/9, 125-133.

Alvarez, D. (2001/2004). Cimento não é concreto, tamborim não é pandeiro, pensamento não é dinheiro! Para onde vai a produção acadêmica? Rio de Janeiro: Myrrha.

Bardin, L. (1987). Análise de conteúdo. Lisboa: Edições 70.

Bourdieu, P. (1989). La noblesse d`Etat. Grandes écoles et esprit de corps. Paris: Minuit.

Bourdieu, P. (1997). Les usages sociaux de la science. Pour une sociologie clinique du champ scientifique. Paris: INRA.

Bourdieu, P. (2001). Science de la science et reflexivité. Paris: Raison d'agir.

Carmo, M. S. (2001). O cientista em formação: o quotidiano de uma pós-graduação de excelência (nível 7 CAPES). Dissertação de Mestrado. Rio de Janeiro: Departamento de Bioquímica Médica-ICB/UFRJ.

De Meis, L., Velloso, A., Lannes, D., Carmo, M. S. \& De Meis, C. (2003). The growing competition in Brazilian science: rites of passage, stress and burnout. Brazilian Journal of Medical and Biological Research, 36(9), 1135-41.

Dejours, C. (1988). A loucura do trabalho. São Paulo: Oboré.

Dejours, C. \& Abdoucheli, E. (1994). Itinerário teórico em psicopatologia do trabalho. Em Dejours, C. \& cols. Psicodinâmica do trabalho: contribuições da escola dejouriana à análise da relação prazer, sofrimento no trabalho. São Paulo: Atlas.

Dejours, C. (1999). A banalização da injustiça social. Rio de Janeiro: FGV.

Easthope, C. \& Easthope, G. (2000). Intensification, extension and complexity of teachers' workload. British Journal of Sociology of Education, 21(1).

Fang, B.; Howell, K. A. (1977). Death anxiety among graduate students. Journal of the American College Health Association, 25(5), 310-3.

Firth, J. (1986). Levels and sources of stress in medical education. British Medical Journal, 292, 1177-80.

Fischer, S. (2000). Jamison discusses high rates of depression at Universities. The Crimson. 24 Oct 2000. Available at http://www.thecrimson.harvard.edu/article.aspx?ref=101974.

Grau, A., Arias, A. \& Ghisays, R. Síntomas depresivos en estudiantes de Psicología (1999). Acta Psiquiatrica $e$ Psicologica de America Latina., 45(3), 234-39.

Heins, M., Fahey, S. N. \& Leiden, L. I. (1984). Perceived stress in medical, law and graduate student. Journal of Medical Education, 59(3), 169-79.

Helmers, K. F., Danoff, D., Steinert, Y. \& Leyton, M 7 Young, S. N. (1997). Stress and depressed mood in medical students, law students and graduate students of McGill University Academic Medicine, 72(8): 708-14

Herzog, D. B., Norman, D. K., Rigotti, N. A. \& Pepose, M. (1986). Frequency of bulimic behaviors and associated social maladjustment in female graduate students. Journal of Psychiatric Research. 20(4), 355-61.

Hudson, S. A. \& O' Regan, J(1994). Stress and the graduate psychology student. Journal of Clinical Psychology. 50(6), 973-77.
Kreger D. W. (1995). Self-esteem, stress, and depression among graduate students. Psychological Reports, 76(1), 34546.

Leta, J. \& De Meis, L. (1996). A profile of science in Brazil. Scientometrics. 35(1), 33-44.

Leta, J. \& De Meis, L. (1999). A Pós Graduação e a formação de recursos humanos para ciência e tecnologia no Brasil, Tese de doutorado. Rio de Janeiro: Departamento de Bioquímica Médica/UFRJ.

Louzada, R. C. R. (2005). Formação do pesquisador, trabalho científico e saúde mental. Tese de doutorado. Rio de Janeiro: Instituto de Psiquiatria/UFRJ.

Louzada, R. C. R. \& Silva Filho, J. F. (2003). Competitiveness is pushing scientists to the edge. SciDev.Net. Science and Development Network. 2 Dec 2003. Available http://www.scidev.net/EditorLetters/index.cfm?fuseaction=read editorletter\&itemid $=19$ \&language $=1$

Minayo, M. C. S. (1994). Pesquisa Social. Teoria, método e criatividade. Petrópolis/RJ: Vozes.

National Academy of Sciences (2000). Graduate Education in the Chemical Sciences. Issues for the $21^{\text {st }}$ Century: Report of a Workshop. Available at www.nap.edu/openbook/0309071305/html.

Nogueira-Martins, L. A., Fagnani Neto, R., Macedo, P. C. M. \& cols. (2004). The mental health of graduate students at the Federal University of São Paulo: a preliminary report. Brazilian Journal of Medical and Biological Research, 37,10, 15191524.

Peixoto, M. C. L. (1994). Escola de pesquisar: estudo sobre a formação do pesquisador. Tese de doutorado. Faculdade de Educação/Universidade Federal do Rio de Janeiro.

Pourmir, I. (1998). Jeune chercheur: souffrance identitaire et désarroi social. Paris/Canadá: L’Harmattan.

Reis, G. A. (1998). A qualidade da formação de doutores e o financiamento a grupos de pesquisa no Brasil: as relações óbvias e as nem tanto. Em M. Palatnik (Org.). A pós-graduação no Brasil. Universidade Federal do Rio de Janeiro.

Sato, L. (1992). O psicólogo e a saúde do trabalhador na área sindical. Em F. Campos, (Org.). Psicologia e saúde. Repensando práticas. São Paulo: Hucitec.

Schneider, A. S. (1998). Harvard Faces the Aftermath of a Graduate Student' s SuicideThe Chronicle of Higher Education $23 \quad$ Oct $1998 . \quad$ Available at http://chronicle.com/chronicle/v45/4509guide.htm [Accessed on 20 jun 2002]

Schwartzman, S. (1979). Formação da comunidade científica no Brasil. São Paulo: Nacional.

Seligmann-Silva, E. (1994). Desgaste mental no trabalho dominado. Universidade Federal do Rio de Janeiro/Cortez.

Slaughter, S. \& Leslie, L. L. (1999). Academic capitalism. Politics, policies and the entrepreneurial university. Baltimore/London: Jonhs Hopkins University Press.

Spiro, J.; Roenneburg, M.; Maly, B. J. (1979/Nov). Medical vs. graduate students: socialization and stress. Annual Conference on Research in Medicine Education, 18, 285-90

Stephan, P. \& Mangematin, V. (1997). Le stress des jeunes chercheurs américains. Biofutur 171, 37-39. 
Towes, J. A., Lockyer, J. M., Dobson, D. J., Simpson, E., Brownell, A. K., Brenneis, F., Macpherson, K. M. \& Cohen, G. S. (1997). Analysis of stress levels among medical students, residents and graduate students at four Canadian schools of medicine. Academic Medicine, 72(11), 997-1002.

Tyssen, R., Vaglum, P., Gronvold, N. T. \& Ekeberg, O. (2001). Factors in medical school that predict postgraduate mental health problems in need of treatment. A nationwide and longitudinal study. Medical Education, 35, 110-120.

Velloso, J. (org) (2002). A pós-graduação no Brasil: formação e trabalho de mestres e doutores no país. Brasília: CAPES.
Vitaliano, P. P., Maiuro, R. D., Russo, J. \& Mitchell, E. S. (1989). Medical student distress. A longitudinal study Journal of Nervous and Mental Disease, 177, 2, 70-76.

Wolf, T. M. (1994) Stress, coping and health: enhacing wellbeing during medical school. Medical Education, 28, 8-17.

Recebido em 27/08/2004

Aceito em 30/08/2005
Endereço para correspondência:

Rita de Cássia Ramos Louzada, Av.
RJ. E-mail: ritacrl@uol.com.br 